\title{
Resistance to cloxacillin among hospital staphylococci
}

\author{
G. C. TURNER ${ }^{1}$ AND P. E. COX \\ From the Department of Pathology, Sefton General Hospital, Liverpool
}

SYNOPSIS Cloxacillin-resistant strains of Staphylococcus aureus were detected by their ability to grow on agar containing $1.6 \mu \mathrm{g} . / \mathrm{ml}$. of cloxacillin, a more reliable method than the disc-diffusion test. $\vec{g}$

At Sefton General Hospital, Liverpool, between 1963 and 1965, there was an increase in the number of infections among in-patients that were caused by staphylococci resistant to cloxacillin or despite the fact that use of the antibiotic was largely confined to an isolation ward for patients with staphylococcal sepsis.

Although there is no evidence yet that staphylococci resistant to cloxacillin will become as 옥 common in hospital practice as those resistant to penicillin and tetracycline it is clear that there is a need for continued vigilance and measures to prevent spread of staphylococci from infected patients.

The last 20 years have seen the emergence of varieties of Staphylococcus aureus resistant to a succession of antibiotics as these have been introduced in turn in hospital practice. Since the appearance of the now commonplace penicillin-resistant staphylococci, which owe their resistance to the production of penicillinase, staphylococci have emerged which are resistant to streptomycin, tetracycline, and usually mercuric chloride; because such strains are now very common among patients in hospital and much less so among others, the term 'hospital staphylococci' is often used to describe them. These strains are also often resistant to erythromycin and sometimes to chloramphenicol; some are resistant to neomycin and these almost always show unusual reactions with typing bacteriophages (Jevons, John, and Parker, 1966).

These multiple-resistant strains usually produce large amounts of penicillinase (Richmond, Parker, Jevons, and John, 1964) and special interest therefore attaches to the introduction and increasing use in hospitals of methicillin (Celbenin) and cloxacillin (Orbenin), the relatively penicillinase-resistant antibiotics derived from the penicillin 'nucleus', 6-aminopenicillanic acid. Because the extensive use of so many antibiotics for the treatment of infections in hospitals has been followed by the appearance of large numbers of strains of Staph. aureus that are resistant to them, it is clearly important to establish whether this can happen with these recent valuable

${ }^{1}$ Present address: Public Health Laboratory, 126, Mount Pleasant, Liverpool, 3.

Received for publication 17 March 1967. additions to the list of antibiotics available for the $\vec{\bullet}$ treatment of staphylococcal infections. Stewart and $\mathcal{g}$ Holt (1963) reported at a children's hospital the isolation from 37 patients, most of them without active infections, of a staphylococcus of phage type 75 resistant to methicillin and cloxacillin. In a general hospital, over a 20-month period, Colley, McNicol, and Bracken (1965) isolated from 73 patients 79 strains of phage group III which were resistant to methicillin and cloxacillin; 61 of these were of phage type $7 / 47 / 53 / 54 / 75 / 77$.

Methicillin was first used at Sefton General Hospital in 1960; cloxacillin followed two years later and because it was suitable for administration either by mouth or by injection, it replaced methicillin (Table I). After 1962 it was the generally accepted policy in

TABLE I

METHICILLIN AND CLOXACILLIN DISPENSED AT SEFTON GENERAL HOSPITAL

\begin{tabular}{cccc} 
Year & Methicillin (g.) & Cloxacillin (g.) & Total (g.) \\
\hline 1960 & 300 & 0 & 300 \\
1961 & 4,050 & 0 & 4,050 \\
1962 & 3,700 & 386 & 4,086 \\
1963 & 900 & 2,802 & 3,702 \\
1964 & 100 & 4,750 & 4,850 \\
1965 & 0 & 3,825 & 3,825
\end{tabular}

the hospital to use cloxacillin for the treatment of all multiple-resistant staphylococcal infections. In this ? article we present a survey of infections caused by staphylococci resistant to cloxacillin which were encountered in patients in the hospital between 1963 and 1965.

Cross-infection between patients is clearly an im- 
portant factor in the emergence in a hospital of antibiotic-resistant staphylococci. In an attempt to reduce this at Sefton an isolation ward with single-room accommodation for patients with staphylococcal sepsis was opened on 1 January 1964 (Turner, Watson, and Abbott, 1965). Subsequently the majority of patients found to have multiple-resistant staphylococcal infections were nursed in the isolation ward. As treatment with cloxacillin was largely confined to patients with infections of this kind, that antibiotic was used extensively in the isolation ward and seldom in the other wards of the hospital. The ward is situated at one end of a single-storey block which also contains six general medical wards; there is a separate nursing and domestic staff but it is necessary for night duty and holiday relief to be provided by staff from other wards.

\section{METHOD OF INVESTIGATION}

During the three years, 1963 to 1965 , a record was maintained of all isolations of coagulase-positive staphylococci from infected lesions, nasal swabs, and other samples from staff and patients in the hospital. Each culture was tested for sensitivity to antibiotics by the disc-diffusion method by inoculation on an agar plate of a $5 \mathrm{~mm}$. loopful of a suspension standardized to Brown's no. 1 opacity tube and application of discs containing penicillin (1 unit), streptomycin $(10 \mu \mathrm{g}$.), tetracycline $(25 \mu \mathrm{g}$.), erythromycin $(5 \mu \mathrm{g}$.), fusidic acid $(10 \mu \mathrm{g}$.), and cephaloridine $(5 \mu \mathrm{g}$.); the depth of the agar in plates used for disc-diffusion tests was 3-4 mm. Tests for sensitivity to cloxacillin and methicillin were as described in the results section. During the period under review, infections by cloxacillin-resistant staphylococci were encountered in 39 patients and the strains from these were made the subject of special study. Cloxacillinresistant strains were also isolated from infections in two nurses and from nasal swabs from four patients not otherwise infected by a cloxacillin-resistant staphylococcus.

All multiple-resistant staphyloccoci were phage-typed.

\section{RESULTS}

PATTERN OF RESISTANCE TO ClOXACILlin All the cloxacillin-resistant staphylococci tested were also resistant to methicillin; and the pattern of resistance to cloxacillin was the same as that described in the case of methicillin by other workers (Sutherland and
Rolinson, 1964; Parker and Jevons, 1964). Thus our cloxacillin-resistant cultures behaved as mixed populations consisting of a majority of cells not a great deal more resistant to cloxacillin than cells of fullysensitive cultures and a small minority of cells able to grow in very high concentrations of the antibiotic.

DETECTION OF RESISTANCE TO CLOXACILliN Cloxacillin-resistant cultures contain highly resistant cells which are not only relatively few in number but also grow in vitro at a slower rate than sensitive cells; they are as a result difficult to detect by the ordinary discdiffusion technique on agar.

We found, in disc-diffusion tests, that resistant cultures showed with discs containing $5 \mu \mathrm{g}$. of cloxacillin or $10 \mu \mathrm{g}$. of methicillin (the concentrations commonly used) zones of inhibition which were reduced in diameter by comparison with that obtained with sensitive cultures. This reduction clearly corresponded to the slightly increased resistance of the majority of cells; but the difference in zone size was not clear-cut because with both sensitive and resistant cultures it varied with inoculum size. On the other hand, with a heavy inoculum (e.g., the sensitivity plate flooded with an overnight broth culture) and after 48 hours' incubation, resistant cultures showed colonies within the zone of inhibition up to the edge of the disc.

Better discrimination in terms of zone size was obtained with a $1 \mu \mathrm{g}$. cloxacillin disc but 48 hours' incubation was still necessary for the adequate growth of resistant colonies.

Altogether clearer definition of resistance was obtained when nutrient agar plates containing serial dilutions of cloxacillin from $100 \mu \mathrm{g} . / \mathrm{ml}$. to $0 \cdot 1 \mu \mathrm{g} . / \mathrm{ml}$. were spot-inoculated with a $5 \mathrm{~mm}$. loopful of an overnight broth culture of each staphylococcus under test. The results, examples of which are shown in Table II, showed that the minimum inhibitory concentration (M.I.C.) of cloxacillin was about $0 \cdot 2 \mu \mathrm{g}$./ $\mathrm{ml}$., for penicillin-sensitive staphylococci, slightly greater for those resistant to penicillin only, and up to $1.6 \mu \mathrm{g} . / \mathrm{ml}$. for multiple-resistant staphylococci; these differences in M.I.C.among cloxacillin-sensitive strains were presumably the result of slow inactivation

TABLE II

GROWTH OF STAPHYLOCOCCI ON CLOXACILLIN AGAR

Typical Strain Cloxacillin in Agar ( $\mu \mathrm{g} . / \mathrm{ml}$.)

Penicillin-sensitive

Resistant to penicillin only

Multiple-resistant, cloxacillin-sensitive

Multiple-resistant, cloxacillin-resistant

$+++=$ maximum confluent growth

\begin{tabular}{|c|c|c|c|c|c|c|c|c|}
\hline $0 \cdot 1$ & 0.2 & 0.4 & 0.8 & $1 \cdot 6$ & $3 \cdot 1$ & $6 \cdot 2$ & 25 & 100 \\
\hline++ & - & - & - & - & - & - & - & - \\
\hline$++t$ & ++ & - & - & - & 一 & 一 & - & - \\
\hline$++t$ & $++t$ & ++ & + & - & - & - & - & - \\
\hline+++ & +++ & +++ & +++ & +++ & ++ & + & + & 5 \\
\hline
\end{tabular}


of cloxacillin by penicillinase (Knox and Smith, 1963) especially by that produced in large amounts by the multiple-resistant strains.

In contrast the cloxacillin-resistant cultures grew well after 24 hours' incubation on concentrations of up to 3.1 or $6.2 \mu \mathrm{g} . / \mathrm{ml}$., depending on the size of the inoculum; moreover after 48 hours' incubationscanty growth was obtained at much higher concentrations with a few (usually less than 10) colonies appearing on agar containing $100 \mu \mathrm{g} . / \mathrm{ml}$. The viable count on agar without cloxacillin from the loopful inoculum was about $5 \times 10^{6}$ colony-forming units. The proportion of cells able to grow in $100 \mu \mathrm{g}$. $/ \mathrm{ml}$. of cloxacillin appeared therefore to be approximately $1: 10^{6}$. Corresponding results were obtained with agar containing methicillin in concentration about four times greater than those of cloxacillin.

We therefore decided to employ the spot inoculation method on nutrient agar containing $1.6 \mu \mathrm{g} . / \mathrm{ml}$. of cloxacillin which would recognize minor degrees of resistance.

CHARACTERISTICS OF CLOXACILLIN-RESISTANT STAPHYLOCOCCI All the strains that grew in very high concentrations of cloxacillin belonged to a few phage group III types including $77,53 / 77$ and 6/7/47/54/75/ 77.

Some strains, including a few of phage type 83A, mainly isolated during the earlier part of the period covered by the investigation, were 'borderline' resistant; they grew on agar containing $1.6 \mu \mathrm{g} . / \mathrm{ml}$., but not at higher concentrations. Examination of the case histories of the patients, from whom these borderline strains had been isolated, showed (Table III) that when cloxacillin had been used in treatment the staphylococcus had been in each case eliminated from the infected lesion; this had not occurred in lesions infected with typical resistant strains. (Cloxacillin had been used in the treatment of patients infected with resistant strains because, in the early stages of the investigation, their resistance had initially escaped detection.) Thus borderline strains behaved in vivo more like sensitive than resistant strains but there is clearly a possibility that their exposure to cloxacillin may lead to the emergence of variants which are more resistant.

Of the 39 strains isolated from infected patients between 1963 and 1965, all were resistant to penicillin, streptomycin, and tetracycline, and 12 to erythromycin. All but one were sensitive to fusidic acid by the disc-diffusion test but with all the cloxacillin-resistant strains heavy inocula gave resistant colonies on agar containing $0.25 \mu \mathrm{g} . / \mathrm{ml}$. of fusidic acid, suggesting a relatively high incidence of fusidic acid-resistant mutants (Hilson, 1962); an exceptional ability to yield antibiotic-resistant variants is to be expected among staphylococci of phage group III (Barber and Burston, 1955). All the cloxacillin-resistant strains were sensitive to cephaloridine by disc-diffusion test; when, however, they were retested by spot-inoculation on agar containing serial dilutions of cephaloridine the M.I.C. of all these strains was greater than $3.1 \mu \mathrm{g} . / \mathrm{ml}$., a finding in agreement with the observations of Ridley and Phillips (1965) on cross-resistance between cloxacillin and cephaloridine. Failure to detect cephaloridine-resistance by the disc-diffusion method was also reported by Burgess and Evans (1966).

No cloxacillin-resistant strains were found among several hundred strains which were sensitive to all the other antibiotics or resistant to penicillin only.

TABLE III

RESPONSE OF CLOXACILLIN-RESISTANT STAPHYLOCOCCAL INFECTIONS TO TREATMENT WITH CLOXACILLIN ${ }^{1}$

\begin{tabular}{|c|c|c|c|c|c|c|}
\hline \multirow[t]{2}{*}{$\begin{array}{l}\text { Resistance to Cloxacillin of } \\
\text { Infecting Organism }\end{array}$} & \multicolumn{2}{|c|}{ Number of Patients } & \multicolumn{4}{|c|}{$\begin{array}{l}\text { Isolation of Cloxacillin-resistant } \text { Staph. aureus from } \\
\text { Treated Patients }\end{array}$} \\
\hline & Infected & $\begin{array}{l}\text { Treated with } \\
\text { Cloxacillin }\end{array}$ & Patient No. & Site & $\begin{array}{l}\text { Before } \\
\text { Treatment }\end{array}$ & $\begin{array}{l}\text { After } \\
\text { Treatment }\end{array}$ \\
\hline Borderline resistant $(1.6 \mu \mathrm{g} . / \mathrm{ml}$. only $)$ & 9 & 6 & $\begin{array}{l}1 \\
2 \\
3 \\
4 \\
5 \\
6\end{array}$ & $\begin{array}{l}\text { Urine } \\
\text { Faeces } \\
\text { Pustule } \\
\text { Urine } \\
\text { Parotid } \\
\text { Sputum }\end{array}$ & $\begin{array}{l}+ \\
+ \\
+ \\
+ \\
+ \\
+\end{array}$ & $\begin{array}{l}- \\
- \\
- \\
-\end{array}$ \\
\hline Resistant (100 $\mu \mathrm{g} . / \mathrm{ml}$. or more) & 30 & & $\begin{array}{l}1 \\
2 \\
3 \\
\\
4 \\
5 \\
6\end{array}$ & $\begin{array}{l}\text { Wound } \\
\text { Wound } \\
\text { Sputum } \\
\text { Wound } \\
\text { Eye } \\
\text { Parotid } \\
\text { Tracheotomy } \\
\text { secretion }\end{array}$ & $\begin{array}{l}+ \\
+ \\
+ \\
+ \\
+ \\
+ \\
+\end{array}$ & $\begin{array}{l}+ \\
- \\
+ \\
+ \\
+ \\
+\end{array}$ \\
\hline
\end{tabular}

${ }^{1}$ Usually $500 \mathrm{mg}$. six-hourly. 
INCIDENCE OF CLOXACILLIN-RESISTANT STAPHYLOCOCCAL INFECTIONS IN THE HOSPITAL Table IV shows for each of the years 1963,1964 , and 1965 the total mumber of in-patients found to have infections caused by multiple-resistant staphylococci and the proportion in which the infecting organism was cloxacillinresistant. The proportion of infections by cloxacillinresistant staphylococci increased three-fold between 1963 and 1965; moreover, in 1963 seven of the eight strains involved were only of borderline resistance, but in 1965 all 22 strains were fully resistant. There was no corresponding increase in the total number of infections caused by staphylococci of phage group III; the yearly incidence was: 1963, 34; 1964, 17; 1965,36 . Thus the proportion of these infections caused by cloxacillin-resistant strains increased sharply; indeed during the last four months of 1965 all 14 phage group III strains isolated from new infections were cloxacillin-resistant.

\section{TABLE IV}

YEARLY INCIDENCE OF STAPHYLOCOCCAL INFECTIONS AMONG IN-PATIENTS

\begin{tabular}{clllll} 
Year & $\begin{array}{l}\text { Number of } \\
\text { Infections by } \\
\text { Multiple-resistant } \\
\text { Staphylococci }\end{array}$ & \multicolumn{4}{l}{ Reaction to Cloxacillin } \\
\cline { 3 - 6 } & Tested & $\begin{array}{l}\text { Border- Resistant } \\
\text { line }\end{array}$ & $\begin{array}{l}\text { All } \\
\text { Resistant }\end{array}$ \\
\hline 1963 & 204 & 149 & 7 & 1 & $8(5 \cdot 4 \%)$ \\
1964 & 138 & 119 & 2 & 7 & $9(7.6 \%)$ \\
1965 & 139 & 132 & 0 & 22 & $22(16.6 \%)$
\end{tabular}

${ }^{1}$ Among the 39 cloxacillin-resistant infections there were five in which the lesion had been infected earlier with a multiple-resistant but cloxacillin-sensitive staphylococcus of another phage-type.

The 39 cloxacillin-resistant strains responsible for these infections were isolated from: wound infections, 15 , sputum 13 , minor sepsis 7 , urine 2 , parotid infection 1 , faeces 1 . The distribution of infections was thus typical of those caused by antibiotic-resistant hospital staphylococci.

WERE THE INFECTIONS ACQUIRED IN HOSPITAL? In 27 patients the infections were first detected 15 or more days after admission and in 10 others, four to 14 days after admission to hospital. The remaining two occurred in patients, who shortly after discharge from the hospital, were readmitted and found within three days to be infected with a cloxacillin-resistant strain. It is almost certain therefore that all the infections were acquired in hospital. Of these infections only three were acquired by patients in the isolation ward; one of these was evidently infected from a nurse who was a nasal carrier of a cloxacillin-resistant strain of the same phage type. Of these three patients, two acquired the infection while being treated with cloxacillin in each case for another infection by a staphylococcus of a different phage type. The other 36 patients presumably acquired their infections in general wards; only one was on cloxacillin treatment when the resistant strain was isolated.

WARD OUTBREAKS In several wards, all infections with cloxacillin-resistant staphylococci over a long period were caused by strains of one phage type (Table V). The infected patients did not, however, always represent an unbroken series of contacts; in the outbreaks in wards $D$ and $E$ there were instances where a gap of weeks separated the development of infection in one patient (soon transferred to the isolation ward) and the appearance of a similar infection in the next patient in the series. Undetected nasal carriage could explain the persistence of staphylococci of one phage type in a ward and this was demonstrated during the outbreak on ward $E$ when nasal swabs were taken from staff and patients in the ward. No staff, but seven patients, were found to be nasal carriers of multiple resistant strains of Staph. aureus; two of the strains were cloxacillin-resistant and of the same phage type as the outbreak strain.

T A B L E V

WARD OUTBREAKS OF CLOXACILLIN-RESISTANT STAPHYLOCOCCAL INFECTIONS

\begin{tabular}{lllll} 
Year & Ward & Phage Type & $\begin{array}{l}\text { No. of } \\
\text { Patients } \\
\text { Involved }\end{array}$ & $\begin{array}{l}\text { Duration of } \\
\text { Outbreak } \\
\text { (days) }\end{array}$ \\
\hline 1963 & A & $6 / 7 / 47 / 54 / 75$ & 6 & 36 \\
$1963-64$ & B & $83 A$ & 3 & 48 \\
1964 & C & $53 / 75 / 77$ & 4 & 11 \\
1965 & D & 77 & 5 & 105 \\
1965 & E & $6 / 53 / 54 / 75 / 77$ & 5 & 89
\end{tabular}

${ }^{1}$ Time between detection of first and last infection.

COURSE OF EVENTS DURING THE WINTER OF 1965-66 More than half the infections by multiple-resistant staphylococci during the months October and November 1965 were caused by cloxacillin-resistant strains (Table VI). This state of affairs was happily short-lived and the first three months of 1966 (not otherwise included in this survey) saw a return to the earlier position with less than $10 \%$ of multipleresistant infections being caused by strains resistant to cloxacillin.

\section{DISCUSSION}

During the years 1963-65 there was an increase in the number of patients in Sefton General Hospital who, during their stay in the hospital, developed infections caused by cloxacillin-resistant staphylococci. This increase occurred despite the fact that, after 1 January 1964, nearly all patients infected with multipleresistant staphylococci were nursed in a separate ward 
TABLE VI

\begin{tabular}{|c|c|c|}
\hline MONTHLY & $\begin{array}{r}\text { DENCE OF STAPHYLO } \\
\text { AMONG IN-PATI }\end{array}$ & I INFECTIONS \\
\hline Month & Number of Infections $b$ & \\
\hline & $\begin{array}{l}\text { All Multiple-resistant } \\
\text { Staphylococci }\end{array}$ & $\begin{array}{l}\text { Cloxacillin-resistant } \\
\text { Staphylococci }\end{array}$ \\
\hline 1965 & & \\
\hline September & 9 & 2 \\
\hline October & 8 & 3 \\
\hline November & 10 & 7 \\
\hline December & 19 & 2 \\
\hline 1966 & & \\
\hline January & 12 & o \\
\hline February & 12 & 1 \\
\hline March & 10 & 2 \\
\hline
\end{tabular}

in single-room isolation; in consequence most of the cloxacillin used in the hospital was given to patients in that ward. Fortunately cloxacillin-resistant strains have not yet appeared in the hospital on a scale comparable to that seen previously with strains resistant to penicillin and tetracycline. Nevertheless, the experience reported here when, from October to December 1965 , cloxacillin-resistant strains were responsible for more than half the new infections by multipleresistant staphylococci emphasizes the need for continued vigilance in dealing with infections by these organisms.

It is clear that a reliable method of recognizing cloxacillin resistance among staphylococci is important and we have found a $1 \mu \mathrm{g}$. better than a $5 \mu \mathrm{g}$. disc when the disc diffusion method is used. We have, however, obtained more clear-cut results by inoculating all cultures under test on agar containing 1.6 $\mu \mathrm{g} . / \mathrm{ml}$. of cloxacillin; growth was obtained at this concentration with all resistant and a few borderline strains.

When a rapid increase in the number of infections by cloxacillin-resistant staphylococci occurred in October and November 1965, we did not advise a general withdrawal of cloxacillin because the antibiotic was used mainly in the isolation ward, where only three of the infections were acquired. So far as we are aware, use of cloxacillin in the isolation ward could have had no direct bearing on the increase elsewhere in the number of infections by staphylococci resistant to cloxacillin; patients known to be still harbouring multiple-resistant Staph. aureus were not transferred from the isolation to general wards (Turner et al., 1965).

It was clear, however, from the relatively large $\frac{?}{0}$ number of these infections which occurred as out- $\frac{\bar{O}}{\sigma}$ breaks in general wards that cross-infection in these $\frac{\overline{\bar{p}}}{\overline{1}}$ wards was responsible for the increase in their inci- $\Phi$ dence. The policy of isolating all patients with such infections was extended in the case of the outbreak in ${ }^{\infty}$ ward E (Table V) to include patients found to be $\vec{O}$ nasal carriers of cloxacillin-resistant staphylococci.

This isolation policy may have been responsible for $\omega$ the fact that the sharp increase in the number of new infections with cloxacillin-resistant staphylococci in the autumn of 1965 was shortlived but it was probably $\bigcirc$ not the only factor. Thus Colley et al. (1965) reported from a hospital in London a month-by-month in- $\stackrel{\infty}{d}$ cidence of methicillin-resistant staphylococcal infec- 0 tions which showed a waxing and waning similar to the pattern described here although, at their hospital, $\vec{z}$ patients with these infections were apparently not

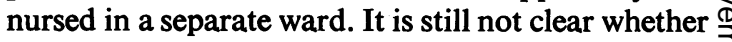
cloxacillin-resistant staphylococci, the more resistant cells of which are relatively slow growing in vitro, have the exceptional ability to spread among hospi- $\vec{\oplus}$ tal patients which is evidently possessed by multipleresistant staphylococci of the 'epidemic' varieties.

We wish to thank our clinical colleagues at Sefton General Hospital for their cooperation, especially in $\bar{O}$ connexion with the isolation and antibiotic treatment of their patients, and for access to case histories; and Dr. $\varrho$ J.D. Abbott of the Public Health Laboratory, Manchester, $\vec{\overrightarrow{ }}$ who kindly phage-typed our staphylococci. Antibiotic sensitivity discs were supplied by Mast Laboratories, Liverpool.

\section{REFERENCES}

Barber, M., and Burston, J. (1955). Lancet, 2, 578.

Burgess, H. A., and Evans, R. J. (1966). Brit. med. J., 2, 1244.

Colley, E. W., McNicol, M. W. and Bracken, P. M. (1965). Lancet, $1,595$.

Hilson, G. R. F. (1962)., Ibid. 1, 932.

Jevons, M. P., John, M., and Parker, M. T. (1966). J. clin. Path., 19, 305.

Knox, R., and Smith, J. T. (1963). Brit. med. J., 2, 205.

Parker, M. T., and Jevons, M. P. (1964). Postgrad. med. J., 40, suppl., 170.

Richmond, M. H., Parker, M. T., Jevons, M. P., and John, M. (1964). Lancet, 1, 293.

Ridley, M., and Phillips, I. (1965). Nature (Lond.), 208, 1076.

Stewart, G. T., and Holt, R. J. (1963). Brit. med. J., 1, 308.

Sutherland, R., and Rolinson, G. N. (1964). J. Bact., 87, 887.

Turner, G. C., Watson, D. C., and Abbott, J. D. (1965). Lancet, 2, W 426. 